\title{
Representações sociais da depressão no contexto escolar
}

\author{
Karla Carolina Silveira Ribeiro \\ Josevânia da Silva Cruz de Oliveira \\ Maria da Penha de Lima Coutinho \\ Universidade Federal da Paraíba, João Pessoa-PB, Brasil \\ Ludgleydson Fernandes de Araújo \\ Universidade Federal do Piauí, Parnaíba-PI, Brasil
}

\begin{abstract}
Resumo: Esta pesquisa objetivou apreender as representações sociais da depressão elaboradas por crianças inseridas no Ensino Fundamental, em uma escola publica em João Pessoa-PB. Participaram 553 crianças, de ambos os sexos na faixa etária entre sete e doze anos. Foram utilizados como instrumentos o CDI - Inventário da Depressão Infantil, empregado como screening na seleção da amostra, e a técnica projetiva Desenho-Estória com Tema, o qual foi analisada pelo modelo proposto por Coutinho. Os dados obtidos evidenciam que a depressão está ancorada principalmente a fatores psicossociais, que são expostos pelas crianças como falta de amigos, pessoa isolada e medo de ser rejeitado. Essas associações são resultados das vivências das crianças, como também das informações e representações vinculados ao seu grupo de pertença. Os resultados implicam na necessidade de práticas preventivas e educacionais nas instituições de ensino com a finalidade de contribuir para uma melhor qualidade de vida desses indivíduos.
\end{abstract}

Palavras-chave: Depressão infantil. Representação social. Escola.

\section{Social representations of depression in the school context}

Abstract: This research aimed to apprehend social representations of depression, held by children, in a Basic Public School in João Pessoa, PB, Brazil. A total of 553 children, both genders, aged between 7 and 12 years, participated in the study. The instruments used were: CDI - Children's Depression Inventory, used in the sample screening process, and the projective technique Drawingstory with Theme, analyzed through the model proposed by Coutinho. The data obtained evidence that depression is mainly based on psychosocial factors, reported by children as lack of friends, isolated person, and fear of being rejected. These associations result from children's experiences, as well as information and representations linked to the group they belong to. Concluding, preventive and educational practices, in teaching institutions, with a view to contributing for a better quality of life of these individualsis are needed.

Keywords: Childhood depression. Social representations. School.

\section{Representaciones sociales de la depresión en el contexto de la escuela}

Resumen: Esta investigación tiene el objetivo de aprender las representaciones sociales de la depresión elaboradas por niños del encino fundamental, en una escuela publica en Joao Pessoa-PB. Participaran 553 niños, de ambos los sexos en la faja de edad entre 7 y 12 años. Fueran utilizados como instrumento el CDI - Inventario de la Depresión Infantil, empreñando como screning en la selección de la muestra, y la técnica projetiva Dibujo - Historia con Tema, el cual fue analizada por el modelo propuesto por Coutinho (2005). Los datos obtenidos evidencian que la depresión esta ancorada principalmente en los factores psicosociales, que son expuestos por los niños como falta de amigos, persona aislada y medo de ser rejitado. Esas asociaciones son resultados de vivencias de los niños, como también de informaciones y representaciones vinculadas a sus grupos. Los resultados muestran la necesidad de prácticas preventivas y educacionales en las instituciones de enseñanza con la finalidad de contribuir para una mejor cualidad de vida deses individuos.

Palabras clave: Depresión infantil. Representaciones sociales. Escuela. 


\section{Introdução}

A Organização Mundial de Saúde (OMS) conferiu à depressão o quarto lugar entre as vinte doenças de maior AVAD (anos de vida perdidos por morte prematura e "incapacidade") e a projeção é de que ela alcance o segundo lugar nos próximos 20 anos (Zavachi e cols., 2002).

A depressão é caracterizada como um transtorno de humor, porém ela abrange fatores cognitivos, comportamentais, fisiológicos, sociais, econômicos e religiosos, entre outros, estando presente em diversos distúrbios emocionais. Pode aparecer como um sintoma de determinada doença, ora coexistir junto com outros estados emocionais e outras vezes aparecer como causa desses sofrimentos (Holmes, 1997). A sintomatologia da depressão pode variar de pessoa para pessoa, fato evidenciado ao se fazer uma analogia entre a depressão e o consumo de drogas: cada personalidade reage de uma maneira própria, o que terão em comum será a utilização da substância.

No percurso da história da depressão e de seus quadros clínicos, a mesma tem sido classificada e conceitualizada de diversas maneiras, ocasionando controvérsias em relação ao termo. Para Lafer e Amaral (2000) é uma sensação inalterável e durável no qual a pessoa se sente sem valor, o mundo não tem significado e se acredita que não há esperança para o futuro.

Para Camon (2001), a depressão surge como resultante de uma inibição global da pessoa, que afeta a função da mente e distorce a maneira como essa vê o mundo, sente a realidade, entende as coisas e demonstra suas emoções. De forma consonante, Del Porto (1999) afirma que a depressão tem sido classificada de várias formas de acordo com a vinculação ao período histórico, à preferência dos autores e ao ponto de vista adotado pelos mesmos.

Devido a essa gama de definições sobre o transtorno, a psicopatologia recomenda como válida a existência de três sintomas depressivos: sofrimento moral, inibição global e estreitamento vivencial (Ballone, 2002). Del Porto (1999) informa que no diagnóstico da depressão levam-se em consideração sintomas psíquicos: humor depressivo, redução na capacidade de experimentar prazer, fadiga ou sensação de perda de energia e uma diminuição na capacidade de pensar. Os sintomas fisiológicos também são contemplados, como as alterações do sono e do apetite e redução do interesse sexual. E, por fim, evidências comportamentais: retraimento social, crises de choro, comportamentos suicidas, retardo psicomotor e lentidão generalizada, ou agitação generalizada.

A depressão pode ser vista como um mal que se enraíza no "eu” do indivíduo, bloqueando suas vontades e dirigindo de forma negativa o curso de seus pensamentos, interferindo no seu autoconceito, prejudicando o sujeito tanto no contexto psicossocial como individual (Coutinho, 2005).

Durante muito tempo a depressão era vista apenas como um problema de adultos. Acreditavase que a depressão em crianças não existia ou então seria muito rara nessa população (Crunivel \& Boruchovitch, 2004). Atualmente é fato que a depressão atinge a infância. Bahls (2002) encontrou o resultado da prevalência/ano para a depressão maior de 0,4 a $3,0 \%$ em crianças e de 3,3 a $12,4 \%$ em adolescentes.

$\mathrm{Na}$ criança os principais comportamentos que caracterizam a depressão infantil são: o humor disfórico, autodepreciação, agressividade ou a irritação, distúrbio do sono, queda do desempenho escolar, diminuição da socialização, perda da energia habitual, do apetite ou peso (Spiz \& Nissen, 1983).

Além de ser prevalente, a depressão tem um impacto considerável e amplo na vida do sujeito. Esse impacto não se restringe à sintomatologia da doença. Pessoas depressivas utilizam os serviços médicos com maior freqüência, tem diminuição da produtividade no trabalho e prejuízo na qualidade de vida quando comparados a portadores de outras doenças crônicas (Fleck e cols., 2002). Em crianças a presença dessa sintomatologia pode interferir diretamente nas atividades associadas à cognição e à emoção. Incide que, quando essa criança não é tratada a tempo, poderá desenvolver modelos de comportamento tais como: isolamento, retraimento, dificuldades em se comunicar, entre outros, os quais podem se tornar resistentes a mudanças (Andriola \& Cavalcante, 1999). 
Na criança, o pessimismo também pode existir e pode manifestar-se desde muito cedo. Freqüentemente, surge através do que Seligman (1995), denominou de "estilo explicativo", que nada mais é do que a maneira como os pais decifram a situação do dia a dia e explicam para o filho.

Para Seligman (1995), o estilo explicativo da criança se desenvolve a partir do estilo explicativo da mãe, de críticas de adultos e, por último, mediante situações de desordem vivenciadas pela criança, como: separação dos pais, mudança da escola, morte de um ente querido e estresse. Dessa forma, os pais ou pessoas significativas têm grande parcela de responsabilidade no aparecimento e na manutenção da depressão na criança (Crunivel \& Boruchovitch, 2004).

Faz-se necessária atenção por parte dos familiares e equipe pedagógica acerca dos sinais e sintomas da sintomatologia depressiva na infância. Pois uma das dificuldades que agrava os sintomas da depressão em crianças deve-se ao fato de que os pais não reconhecem os sintomas observados em suas crianças e são incapazes de descrever seus filhos como seres imperfeitos. Outra dificuldade é a diferenciação de comportamento apresentado pela criança quando se refere ao contexto familiar e escolar (Coutinho, 2005).

Segundo Puig-Antich, (1986), a maior parte da sintomatologia depressiva é intrapsíquica, as próprias crianças são os melhores comunicadores de seu mundo interior. A partir de seis anos de idade, elas são capazes de identificar sua sintomatologia depressiva.

Diante desse quadro teórico e das dificuldades das crianças de conceituar seu sofrimento, optou-se, portanto, ancorar este estudo à teoria das representações sociais (RS), o qual possibilita o reconhecimento das RS da sintomatologia da depressão infantil a partir de um conhecimento elaborado e compartilhado pelas crianças. Partindo desse princípio objetiva-se, com esta pesquisa, a criação de uma base de dados que identifique o processo no qual se constrói o conceito e a identificação do sujeito com o objeto.

Todos os fenômenos que surgem do contexto social são acometidos simbolicamente, ou seja, recebem nomes e significados que os avaliam, explicam e lhes dão sentido. Esses significados, à medida que circulam, transformam-se e assumem formas diferentes, de acordo com os modelos vigorantes em uma determinada época e formação social. Sabe-se, ainda, que esses significados são resultantes da influência mútua entre o senso comum e a ciência, através dos meios de comunicação formais e informais, assimilados e reelaborados socialmente (Vala, 2000).

Nesta perspectiva Barros e Coutinho (2005) relatam que o objetivo das representações sociais não se restringe à tentativa de conhecer o que existe nas mentes dos indivíduos, mas prolongar-se para além das dimensões intrapsíquicas e concretizar-se em fenômenos sociais possíveis de serem identificados e mapeados.

Para Moscovici (1961), as representações sociais procuram dar conta de um fenômeno em que o homem manifesta sua capacidade inventiva para apossar-se do mundo por meio de conceitos, afirmações e explicações, originados no dia a dia, nas influências sociais mútuas, a respeito de qualquer objeto, social ou natural, para torná-lo familiar e garantir comunicação no interior do grupo e interatuar com outras pessoas e grupos.

A história das representações sociais sobre saúde e doença foi sempre pautada pela inter-relação entre os atores sociais e o contexto que os rodeia. A doença pertence não só à história profunda dos progressos científicos e tecnológicos, como também à história profunda dos saberes e das práticas ligadas às estruturas sociais, às instituições e às representações (Le Goff, 1991).

Quando uma doença surge na vida de um indivíduo, traz consigo alterações e transformações não só no organismo como também no modo de vida e nas relações sociais desse indivíduo. Observou-se nas duas últimas décadas que houve um aumento muito grande do número de casos de depressão na infância. Frente a essa realidade a criança constrói representações que lhes auxiliam na atribuição de sentido para orientar seus comportamentos no decorrer da experiência com a doença (Coutinho, 2005).

Para Doise (1990), a utilização da teoria das RS no diagnóstico psicossocial é bastante útil, tendo 
em vista que a mesma envolve tanto o nível intrapessoal de análise como o interpessoal e o grupo, permitindo a partir daí as representações pessoais de objetos sociais, para um exame das cognições no nível grupal, que permitam ao pesquisador a apreensão dos aspectos compartilhados de uma representação.

Segundo Abric (1987), a representação social pode ser analisada como produto e como processo de uma atividade mental pela qual um indivíduo ou um grupo reconstitui o real com o qual ele é confrontado e lhe confere um sentido específico. Corroborando com essa perspectiva, Jodelet (2001) afirma que as RS tratam-se de um sistema cognitivo, uma organização psicológica que estabelece uma relação entre o indivíduo e o social e que consente aos indivíduos e grupos uma convergência através da comunicação que se dá no processo de estruturação e na dinâmica que preside o conhecimento.

O universo de opiniões particulares que pertencem a cada grupo é produto de uma comunicação na qual a mensagem passa por uma decodificação, isto é, ela é deformada, diferenciada, traduzida, da mesma forma que os grupos criam, deformam ou traduzem os objetos sociais de outras populações. Desta forma, o social não é apenas o cenário, ele gera as Representações Sociais (Coutinho, 2005).

Assim, as Representações Sociais podem ser vistas como o conjunto organizado de informações, atitudes, crenças que um sujeito ou um grupo elabora a propósito de um objeto, de uma circunstância, de um conceito, de outros indivíduos ou grupos, apresentando-se, portanto, como uma visão subjetiva e social da realidade (Abric, 1987; Oliveira, Sá, Fischer, Martins \& Teixeira, 2001). A função essencial das RS, para aqueles que representam, é tornar aquilo que não é familiar em algo familiar, próximo e prático (Moscovici, 2003).

Em resumo, ao ser produção simbólica dedicada a compreender e balizar o mundo, ela procede de um sujeito ativo e criativo, tem um caráter cognitivo e autônomo e configura a construção social da realidade. A ação e a comunicação são seu berço e chão: delas derivam e a elas retornam a representação social (Arruda, 2002).
Com a intenção de aprofundar e enriquecer o debate sobre a temática dessa fase da vida, que pode ser analisada sob diferentes ângulos, este artigo aborda a infância de forma original: a compreensão que a crianças tem sobre a depressão e, conseqüentemente, o sentimento que ela possui em relação a si mesma, frente a essa patologia, seus valores e apreensões. Investiga, portanto, os fatores psicossociais que interferem na etiologia da depressão de infantes inseridos em uma escola pública da cidade de João Pessoa, Paraíba. Essas representações estão tanto na "cultura quanto na cognição" (Farr, 1994), circulando na comunicação social cotidiana e diferenciando-se segundo os grupos sociais (Sá, 1996).

\section{Método}

\section{Campo de investigação}

O presente trabalho foi realizado em uma escola da rede pública de ensino, localizada na cidade de João Pessoa - PB. A escolha dessa instituição se deu por essa ser um marco em educação entre as escolas públicas da região, apresentando um ótimo nível em educação, pois funciona como uma cooperativa com a participação dos pais. Outro fator que contribui para a escolha da instituição deve-se ao fato de que a mesma recebe alunos de todos os bairros, tanto centrais como periféricos, possuindo assim uma diversidade sociocultural e uma abrangência sociodemográfica dos sujeitos ali inseridos, fato este fundamental para a escolha da escola. A realização desse estudo deveu-se a pesquisas realizadas por Barbosa e Gaião (2001), nas quais foi encontrada uma alta incidência $(22 \%)$ de sintomatologia depressiva em crianças desse estado.

\section{Participantes}

A amostra foi não-probabilística, intencional e acidental. Como critérios de inclusão dos sujeitos na constituição da amostra estabeleceu-se que os participantes deveriam aceitar participar do estudo; cursar da segunda à sexta série do ensino fundamental; ter idade mínima de sete anos e máxima de 12 anos e não apresentar outros sintomas de psicopatologia. 
Inicialmente a pesquisa foi realizada com 370 crianças estudantes da segunda à sexta série do ensino fundamental, nas quais foi realizado o procedimento de aplicação do CDI (Children's Depression Inventory), instrumento que foi utilizado como screening na seleção da amostra. Tais crianças possuíam faixa etária variando de 7 a 12 anos, com uma média de 10,24 anos e desvio padrão de 1,44, sendo 45,1 do sexo masculino e 54,9 do sexo feminino, apesar da não equivalência de gêneros, não se considerou como foco para compreensão da sintomatologia depressiva na infância, pois de acordo com Grillo e Silva (2004), na infância o risco de depressão é o mesmo em meninos e meninas.

A partir do CDI foram detectadas 22 crianças (5,95\% da população) com pontuação acima do ponto de corte 17 na escala - indicativo de sintomatologia depresiva, constituindo, assim, a amostra definitiva.

\section{Instrumentos}

CDI (Inventário de Depressão Infantil)

Foi utilizado o CDI (Children's Depression Inventory), elaborado por Kovács (1992), que constitui uma adaptação do BDI (Inventário de Depressão de Beck). No entanto, o instrumento utilizado neste estudo foi uma forma ajustada e normatizada por Barbosa, Dias, Gaião e Lorenzo (1995) em uma população brasileira. O instrumento aqui utilizado é composto por 20 itens e cada item consta de três opções de resposta com um valor correspondente $(\mathrm{a}=1, \mathrm{~b}=2, \mathrm{c}=3)$, com um ponto de corte (somatório) 17. É recomendado para uma faixa etária entre sete e 17 anos e tem sido utilizado como instrumento de screening na identificação de crianças com alterações afetivas, alterações de humor, da capacidade de sentir prazer, das funções vegetativas, de auto-avaliação e de outras condutas interpessoais (Coutinho, 2005).

Desenho-Estória com Tema

O segundo instrumento a ser aplicado foi a técnica projetiva Desenho-Estória com Tema. A criança demonstra uma dificuldade de expressão, principalmente quando se refere a sentimentos que evocam tristeza, medo, rejeição afetiva ou sentimentos agressivos. $\mathrm{O}$ desenho possibilita a emersão de conteúdos conflituosos tanto conscientes como inconscientes (Campos, 2005; Coutinho, 2005).

Este instrumento foi desenvolvido a partir do procedimento Desenho-Estória (Trinca, 1976), constituindo uma técnica temática e gráfica com a finalidade de compreender elementos com vistas à ampliação de dados do dinamismo da personalidade, podendo ser aplicado a todas as faixas etárias, níveis econômico e mental (Campos, 2005; Coutinho, 2005).

\section{Procedimentos de coleta dos dados}

Inicialmente a pesquisa foi aprovada pelo Comitê de Ética em Pesquisa com seres Humanos do CCS (Centro de Ciências da Saúde) da UFPB, onde foram averigüados os parâmetros éticos, tendo como base à resolução $n^{\circ}$ 196/96. Posteriormente, realizou-se contato com a direção da instituição de ensino público e foi obitido o termo de Concordância para realização da pesquisa. Em seguida, encaminhouse o Termo de Consentimento Livre e Esclarecido aos pais ou responsáveis das crianças. Após a confirmação dos responsáveis, foram agendadas visitas à escola para a aplicação do CDI e do Desenho-Estória com Tema, por pesquisadores previamente treinados.

$\mathrm{O}$ estudo foi efetivado em duas etapas. A primeira constituiu-se na aplicação do CDI, o qual foi aplicado de forma coletiva, realizada por quatro pesquisadores, na sala de aula, sendo entregue o material às crianças (o questionário), com as devidas instruções: "Vocês vão responder este questionário. Cada pergunta é composta por três opções, escolha uma delas e marque com um X, marque apenas uma e, por favor, não deixe nenhuma em branco. Vocês têm alguma duvida?”. Após o recolhimento dos questionários, foram feitos os somatórios dos itens e aquelas crianças que apresentaram uma pontuação superior a 17 pontos foram selecionadas para compor a amostra definitiva.

A segunda etapa do estudo consistiu na aplicação do Desenho-Estória com Tema. O tempo de duração foi em média 15 minutos, sendo realizada de forma individual, com dois pesquisadores previamente treinados. Antes da aplicação do estímulo, os pesquisadores informaram aos partici- 
pantes que as atividades não receberiam nota e os desenhos seriam analisados em conjunto, o que manteria o anonimato. Posteriormente, foi entregue o material (folha branca e lápis preto $n^{\circ} 2$ ) e, em seguida, foi aplicado o estímulo indutor: "Desenhe uma pessoa com depressão". Ao término do desenho, foi solicitado à criança que "conte-me uma estória sobre o mesmo, que tenha início e fim".

A aplicação dos instrumentos transcorreu tranqüilamente, não havendo nenhuma dificuldade quanto à compreensão semântica dos mesmos. Também não foi verificada nenhuma resistência por parte das crianças em participar da presente pesquisa.

\section{Análise dos Dados}

No que se refere à análise dos dados desta pesquisa, utilizou-se o modelo proposto por Coutinho (2005). Inicialmente, realizou-se uma observação sistemática dos desenhos e temas; em seguida, selecionaram-se os desenhos por semelhança gráfica e/ou aproximação dos temas. No que se refere às estórias, foram categorizadas por meio da Análise de Conteúdo Temática de Bardin (2002), nas seguintes etapas operacionais: leitura flutuante das unidades temáticas, recorte e categorização das mesmas e, por fim, análise e interpretação dos conteúdos temáticos agrupados por categorias e dos desenhos por meio do grafismo. É válido salientar que, neste estudo, foi agrupada a categoria temática de acordo com o consenso de dois juízes especialistas.

\section{Resultados}

A partir da análise realizada nos desenhosestória com tema, seguem-se os que apresentaram características da sintomatologia da depressão infantil, que foram classificados de acordo com semelhanças no grafismo e das estórias comuns. Os desenhos foram classificados em apenas uma categoria: Psicossocial e em três subcategorias: Depressão associada à falta de amigos; Depressão associada ao isolamento e Depressão associada ao medo de rejeição.

\section{Aspectos Psicossociais}

Depressão associada à falta de amigo

Estória: "A menina está com depressão, ai as amigas dela nem percebe ai não vão conversar com ela, dai ela começa a melhorar da depressão."
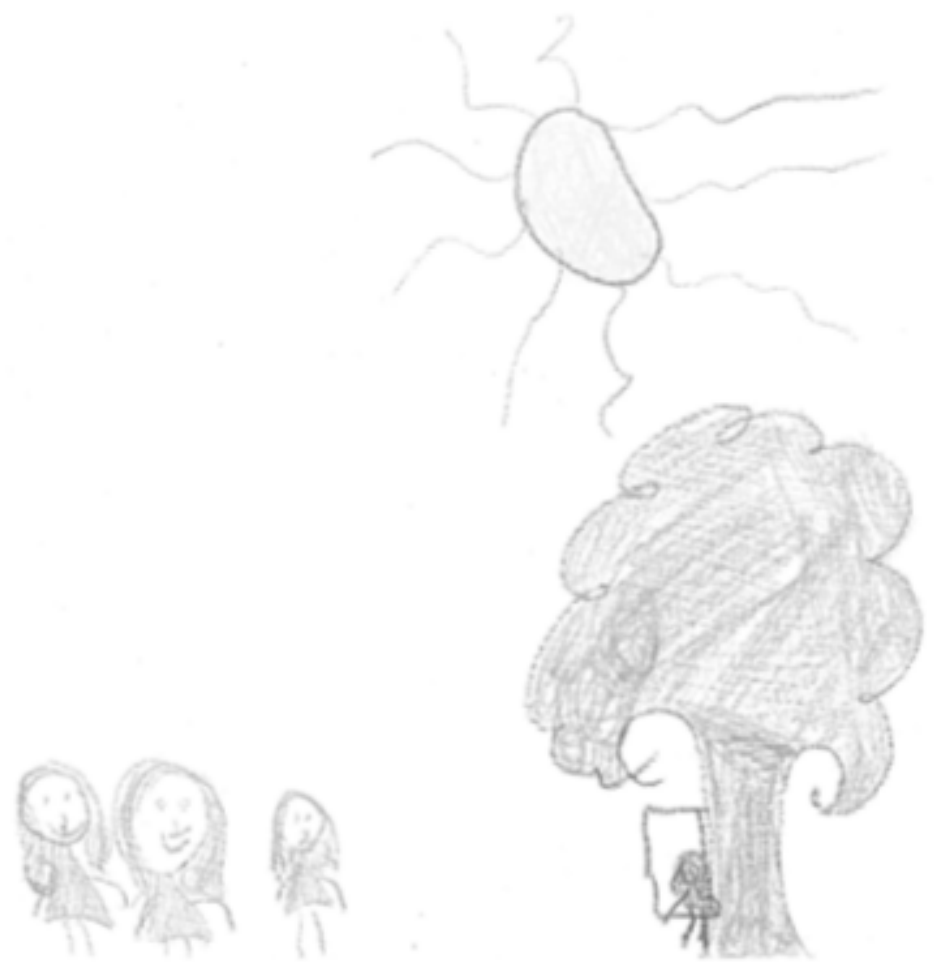

Figura 1. Desenho-Estória com Tema. 


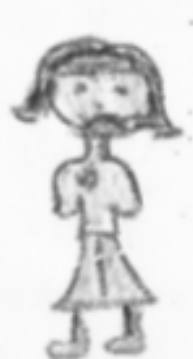

Figura 2. Desenho-Estória com Tema.

Estória: "Ela está sozinha não gosta de brincar por falta de amizade que não consegue ter. Os outros nem se importa."

De acordo com as Figuras 1 e 2, a sintomatologia da depressão, para os participantes desta pesquisa, está ancorada na esfera psicossocial. A falta de amizade ou de companhia de seus pares aparece representada no grafismo pelo distanciamento entre as figuras. $\mathrm{O}$ primeiro desenho mostra uma relação de inferioridade que é objetivada através do tamanho, uma criança representada com tamanho diminuto em comparação às outras à esquerda da página, em relação as quais apresenta uma determinada distância, o que demonstra um sentimento de solidão. Esta situação também é representada por meio dos galhos da árvore encurvada e do sol ao centro, o que vem comprovar uma necessidade de proteção.

Nas Figuras 1 e 2 aparece o distanciamento e a solidão, porém o ser deprimido é desenhado com riquezas de detalhes, em contraposição às outras ilustrações apresentadas, evidenciando um desejo de ser observado e de obter atenção. A figura do ser deprimido é ilustrada com ausência dos membros superiores, o que ratifica um sentimento de menosvalia e distanciamento em relação ao mundo exterior. Porém, neste grafismo o que evidencia a falta de amizade é a ligação, mãos unidas, nos desenhos rudimentares que caracterizam seus pares.
A produção das estórias corrobora os achados do grafismo, mostrando claramente os elementos de solidão, sentimento de baixa auto-estima e dificuldades nos relacionamentos sociais:

Estória: "Ela está sozinha não gosta de brincar por falta de amizade (...) os outros nem se importam (...) as amigas dela não percebem (...) não vão conversar com ela".

Depressão associada ao isolamento

Estória: "Tinha uma pessoa que tinha sua família e acabou destruindo toda a sua família e ela acabou se escondendo por causa da depressão, ela se escondia e se encolhendo num canto qualquer da casa. Sua família se preocupou com suas atitudes e sua família o internou, depois de um tempo ele se tratou, se recuperou e viveu com sua familia."

Na Figura 3 emerge a representação social da depressão associada ao isolamento. No grafismo, a localização da figura humana, desenhada no canto da página, indica uma fuga ou um desajuste do indivíduo ao ambiente, o que também é evidenciado pela posição sentada do esboço e dos membros, superiores e inferiores, presos ao corpo, indicativos de inibição e fraca energia para responder a estímulos 


\section{Figura 3. Desenho-Estória com Tema.}

externos. Outras características factuais da sintomatologia depressiva se exprimem nos olhos oblíqüos para baixo e a boca com expressão lamuriosa (arqueada para baixo), o que vem acentuar um sentimento de impotência, tristeza e debilidade consciente, que apresenta quem tem o isolamento como mecanismo de defesa.

$\mathrm{Na}$ produção da história emergiu a mesma temática, a qual vem corroborar com os achados do grafismo, como pode ser observada nos trechos a seguir:

Estória: “(...) acabou destruindo toda a sua família e ela acabou se escondendo por causa da depressão, ela se escondia $e$ se encolhendo num canto qualquer da casa (...) sua familia o internou”.

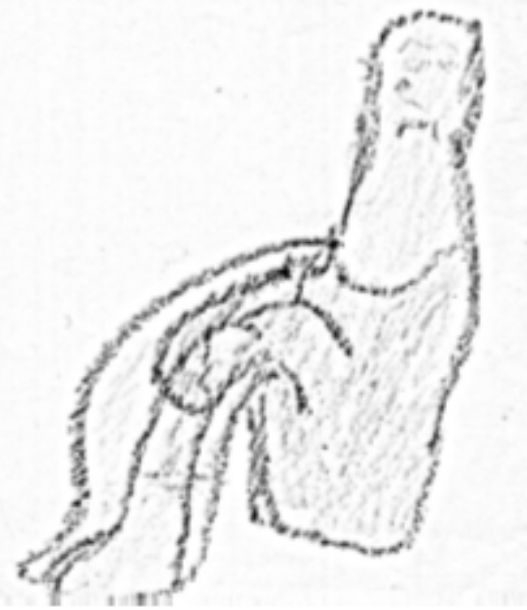

Depressão associada ao medo de rejeição

Estória: "Era uma vez uma garotinha que tinha depressão, então esta garota freqüentemente ela chorava muito na cama por motivos pessoais. Um dia ela saiu com dois amigos para a praça, e ela ficava se perguntando várias vezes se eles gostariam (ficavam felizes) que ela estivesse ali com eles."

Nesta categoria a representação que emerge da sintomatologia depressiva é o medo de se sentir rejeitado. A Figura 4 seguiu a mesma seqüência transcrita pela estória, no canto esquerdo, de tamanho diminuto, uma cama e uma figura sobre ela, o que concebe uma fuga ou desajuste do indivíduo em 


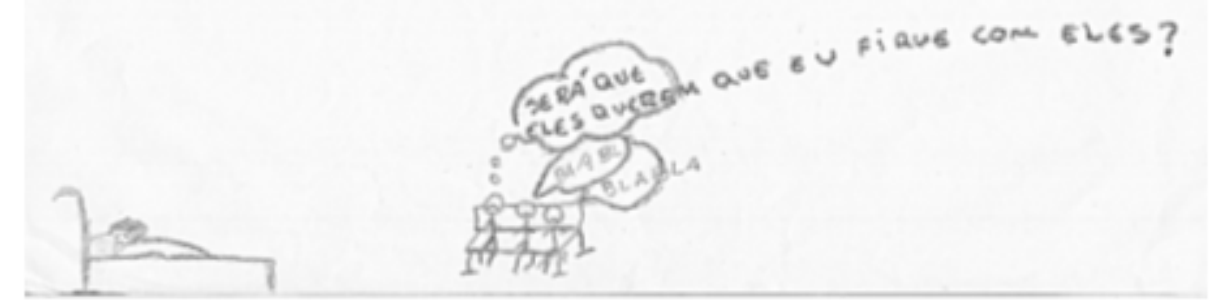

\section{Figura 4. Desenho-Estória com Tema}

relação ao ambiente, tristeza e introspecção, características que remetem à esfera psicoafetiva.

No centro da página encontramos um seguimento da exposição da estória: três figuras idênticas, de mesmo tamanho, sentadas em um banco, dialogando. O que as diferenciam são os balões presentes, que representam as falas dos sujeitos. Em uma delas a criança se questiona se os amigos desejam sua presença, demonstrando insegurança e medo de ser rejeitada. Em seu conjunto é possível observar um grafismo que caracteriza um ser introvertido, galgado de tristeza, sofrimento, refletindo assim uma insegurança em relação a laços e contatos afetivos, provocando no ser uma preocupação de não ser aceito, de ser rejeitado por seus pares, fatos que podem ser observados no transcorrer da história com tais relatos:

Estória: “(...) esta garota freqüentemente ela chora muito na cama (...) ela saiu com dois amigos (...) e ela ficava se perguntando várias vezes se eles gostariam (ficavam feliz) que ela estivesse ali com eles."

Em síntese, os resultados apreendidos pelo instrumento desenho-estória com tema apresentam o ser depressivo como pessoa isolada, sem amigos e com medo de ser rejeitado, estando estas representações ancoradas na esfera psicossocial, demonstrando um comprometimento do infante de estabelecer laços afetivos e sociais com seus pares e familiares.

\section{Discussão}

Em crianças os sintomas depressivos variam de acordo com a faixa etária e, como elas ainda não são capazes de descrever seus sentimentos verbalmente, é indispensável observar as formas de comunicação pré-verbal, tais como a expressão facial, produções gráficas, súbitas mudanças de comportamento e postura corporal, entre outras (Baptista $\&$ Golfeto, 2000).

Nesse estudo, observou-se que a representação social da sintomatologia depressiva em crianças está ancorada na esfera psicossocial, na qual o ser deprimido é visto como aquele que não possui amigos, isolado e que tem medo de ser rejeitado. Portanto, verificou-se um elo significativo intracategorias, distribuídas em dois pólos: a depressão como sintoma (falta de amigos e isolamento) e como possível causa (medo de ser rejeitado).

Constata-se, portanto, a existência de dificuldades relacionadas às relações interpessoais, dificuldade de interação com outras crianças, provavelmente pelos sentimentos de baixa auto-estima presentes nestes indivíduos.

A primeira subcategoria, Falta de Amigos, corresponde a $50 \%$ das representações associadas à depressão na população estudada, sintoma este que pode ser descrito como estreitamento vivencial, sendo caracterizado por Ballone (2002) como um dos três sintomas depressivos.

Ao analisarmos os dados sob o prisma infantil, pode-se observar que o distanciamento dos seus 
pares representa para a criança uma negação de si mesma, não possibilitando ao infante uma identidade social. Corroborando com os achados, Barros e Coutinho (2005) descrevem este comportamento como sendo indicativo da destruição da pessoa, associado a um sentimento de desamparo vivenciado nas práticas sociais.

Barreto (1993) preconiza que a depressão pode estar associada a um comprometimento da personalidade, baixa auto-estima e autoconfiança; e no âmbito social, a depressão representa uma inadaptação ou um apelo ao socorro, bem como uma possível conseqüência da violação de mecanismos culturais, familiares e escolares.

Em crianças de faixa etária entre 6 e 12 anos os sintomas da depressão podem se apresentar como a inabilidade em se divertir (anedonia), pobre relacionamento com seus pares e baixa autoestima, se descrevendo como estúpidas, bobas ou impopulares (Bahls, 2002).

Essa falta de relacionamento entre seus pares, que é o tema central demonstrado no grafismo, traz em si a tristeza como fator primordial, sentimento esse que não é verbalizado pelos infantes, entretanto se apresenta em todos os desenhos por meio do olhar, de lágrimas, da posição da boca, isto é, nas expressões faciais. Detalhes esses que vêm ao encontro de informações trazidas por alguns autores, os quais relatam a ocorrência de fisionomia triste, comunicação deficiente, choro freqüente em crianças pré-escolares com sintomatologia depressiva. O prazer de brincar ou ir para a pré-escola diminui ou desaparece e as aquisições de habilidades sociais próprias da idade não ocorrem naturalmente (Goodyer, 1996; Souza, 1984; Versiani, Reis \& Figueira, 2000).

A anedonia presente nas crianças deprimidas ocasiona falta de interesse em jogos, programas de $\mathrm{TV}$ e outras atividades. $\mathrm{O}$ infante também relata ficar entediado o tempo todo ou confessa que nada mais é divertido. Portanto, o desinteresse em passar um tempo com os amigos e o afastamento dos outros também são comuns (Friedberg \& McClure, 2004).

Confirmando esses achados Calderaro e Carvalho (2005), ao estudarem manifestações depressivas em crianças de 3 a 10 anos de idade, no contexto de creches e saúde pública, na cidade de
Paranavaí-PR, verificaram que a depressão no infante pode ter início com perda de interesse pelas atividades que rotineiramente eram interessantes, como estar entre amigos, participar de brincadeiras, entre outras. De forma complementar aparece perda de confiança em si mesmo, sentimento de inferioridade e baixa auto-estima, idéias de culpa e inutilidade.

Os resultados apresentados na segunda subcategoria vêm reafirmar os entendimentos descritos na categoria anterior, na qual prevalece a ênfase na esfera psicossocial, tendo como pano de fundo a presença da solidão, porém o que as difere é o enfoque dado às associações feitas pelas crianças. Esses dados são corroborados pelas próprias vivências dos infantes, tendo como princípio o fato que a população pesquisada apresenta sintomatologia depressiva.

Segundo Friedberg e McClure (2004) a apatia presente em infante com sintomatologia depressiva é um dos fatores que gera a recusa de convites para visitar amigos, a criança deprimida muitas vezes não recebe tais convites devido aos seus comportamentos socialmente retraídos. Portanto, seu contato social é significantemente enfraquecido, ocasionando sentimentos aumentados de solidão, o que as leva a sentimentos depressivos mais profundos.

Sentimentos de impotência, tristeza e desajuste com o meio, na infância tendem a ter conseqüências preocupantes no desenvolvimento cognitivo, afetivo e comportamental desses sujeitos, como baixo desenvolvimento escolar e dificuldade em socialização. Em pesquisa sobre o rendimento escolar em crianças de nove a doze anos com sintomas depressivos, de uma escola particular na cidade do Recife-PE, Bandim, Roazzi e Doménech (1998) obtiveram como resultado um prejuízo significativo no desempenho escolar em todas as matérias, quando comparadas com crianças sem sintomas depressivos.

Ballone (2004) esclarece esses dados ao relatar que, na fase escolar, o cansaço, a dificuldade de concentração, as alterações da memória, a astenia e adinamia são as complicações da depressão infantil que afetam muito o rendimentos escolar e a aprendizagem. O confronto entre depressão e fracasso escolar acaba fazendo com que o nível de auto-estima também se comprometa, podendo levar a criança a apresentar desde isolamento social até transtornos de conduta. 
Dados atuais têm demonstrado que o início da depressão tem ocorrido cada vez mais cedo na vida. Entretanto, as dificuldades para o diagnóstico na infância estão associadas também às limitações da criança em identificar e descrever emoções (Lagges \& Dunn, 2003), fator este que contribui para o isolamento e sentimentos de culpa, principalmente relacionada a problemas familiares, como perda de um pai ou ente querido, abuso ou negligência e separação dos pais (Palosaari \& Aro, 1994).

Ao pesquisar a nosográfica da sintomatologia depressiva, constatou-se que a mesma se tornou alvo de investigações mais detalhadas a partir da década de 1970, passando a ser sinônimo de preocupação para os profissionais de saúde, uma vez que essa patologia traz comprometimentos importantes nas funções sociais, emocionais e cognitivas, como isolamento, tristeza, autodepreciação, entre outros, interferindo no desenvolvimento infantil, de maneira a afetar não só a criança, como também sua família e o grupo com o qual se relaciona (Miller, 2003; Reis \& Figueira, 2001; Scivoletto \& Tarelho, 2002).

Em pesquisa com crianças com sintomatologia depresiva, realizada por Oliveira, Ribeiro, Araújo e Coutinho (2006) na cidade de João Pessoa, Paraíba, constatou-se que o sentimento de solidão e isolamento é predominante nessa população, demonstrando a importância das relações sócio-afetivas como manutenção/preservação do bem-estar psicossocial da pessoa.

A associação presente na última categoria, como em todo o transcorrer dos resultados, demonstrou relação entre envolvimento com os pares e com o meio e a sintomatologia depressiva. Para os sujeitos aqui estudados, analisando o conjunto das associações, a falta de amigos e o isolamento podem ser vistos como sintomas de um medo inconsciente de rejeição, de não ser aceito.

Lima (2004) relata que crianças com sintomatologia depressiva podem apresentar sintomas como fobias, sintomas somáticos, retraimento social, agressão, medo da morte e enurese. Nesse ponto os achados de Pearce (1978), em pesquisa realizada com crianças depressivas, apresentavam sintomas comuns, com base em dados estatísticos: recusa a ir à escola, percepção alterada, como delírios ou idéias supervalorizadas de culpa e desvalorização de si mesmo.
De forma semelhante aos achados desta pesquisa, Ajuriaguerra e Marcelli (1991) destacam que a depressão infantil está associada a uma inibição motora, ocasionando para a criança uma dificuldade de brincar, executar tarefas ou ocupações. Esses comportamentos são caracterizados como uma desvalorização pessoal que se exprime habitualmente no contexto da sintomatologia depressiva.

Dentre os fatores mais comuns relacionados à depressão infantil predominam: a hiperatividade, sentimento de rejeição, agressividade e isolamento. Esses fatores podem ser ocasionados por problemas no repertório comportamental da criança, que podem ser explicados por uma dificuldade em estabelecer contato ou ser assertiva com outras pessoas em seu meio (Lima, Garcia \& Figueiredo, 2005).

Coutinho (2005), após realizar uma pesquisa com crianças em escolas públicas e particulares da cidade de João Pessoa-PB, verificou que o sentimento de rejeição é um dos mais penosos afetos que um indivíduo pode experimentar e que, comumente, encontra-se quase sempre associado aos sentimentos de perda, falta de amor, desvalorização, perda de autoestima e frustração, sentimentos apontados por nosso sujeito através do grafismo.

Portanto, percebemos que a relação entre sujeito (crianças) e objeto (depressão) demonstra uma familiaridade que provém da vivência com a patologia e da comunicação exercida com os pais e pares. Assim, as crianças entendem que a depressão se configura pela ausência de relação social e se vêem como seres isolados e que demonstram uma imensa dificuldade em estabelecer um nível mais profundo de contato social, o que provoca nas mesmas medo de serem rejeitadas, desencadeando um ciclo repetitivo de temor e isolamento.

A descrição da depressão ancorada em elementos psicossociais demonstra a necessidade de estudos que focalizem não apenas uma perspectiva intraindividual, e sim um objetivo social, uma vez que estabelece conflitos sociais que comprometem a saúde mental do indivíduo e, conseqüentemente, danifica todas as redes de comunicação e convívio, interferindo assim no equilíbrio do meio social e familiar de uma forma muito mais ambrangente. 


\section{Considerações Finais}

As representações sociais da sintomatologia da depressão infantil, tendo como base o saber elaborado e compartilhado pelas próprias crianças, permitiu evidenciar as maneiras pelas quais as mesmas são construídas coletivamente. Portanto, este estudo permitiu a elaboração de uma base referencial explicativa que beneficia as discussões acerca desse fenômeno.

A técnica de desenho-estória com tema, por meio dos grafismos dos participantes, possibilitou o alcance dos objetivos iniciais da pesquisa, demonstrando que as crianças atribuíam significados às suas vivências, tendo como marco o meio social.

Destaca-se nesse estudo a ausência de ancoragem na esfera psicoafetiva, biológica e espiritual. Estes dados apontam para coesão das representações da população infantil desta instituição, onde prevaleceu o fenômeno como um problema de origem psicológica e social, podendo ser um indicativo do conhecimento compartilhado no meio psicossocial no qual as crianças estão inseridas, família, escola, igreja, entre outras. Sugerem-se, assim, futuras investigações com o intuito de averigüar a origem social que desencadeou o unidirecionamento desse fenômeno, como também se essas representações se fazem presentes apenas em alunos do setor público.

Os infantes demonstraram que o isolamento e a ausência de interação social pode ser um indicativo de sintomatologia depresiva. Neste sentido, o setor educacional demonstra ser um locus privilegiado para utilização da observação, tendo em vista que as crianças desfrutam de um tempo significativo do seu cotidiano nessas instituições de ensino. Deste modo, destaca-se a importância do psicólogo escolar e da equipe pedagógica, dada sua capacidade e abrangência, sendo um aliado importante para a solidificação de ações de promoção de saúde voltadas para o fortalecimento das capacidades dos indivíduos e para a tomada de decisões favoráveis à saúde.

Portanto, educadores e pais, ao terem uma melhor compreensão dos fatores psicossociais, presentes neste estudo, que interferem na etiologia da depressão, podem se fazer mais presentes nas práticas preventivas e educacionais nas instituições de ensino, abarcando acompanhamento psicológico e familiar, com a finalidade de contribuir para uma melhor qualidade de vida na infância.
Espera-se, assim, que esta pesquisa possa contribuir para uma melhor compreensão da sintomatologia depressiva na infância, como também fornecer contribuições na elaboração de práticas curriculares nas instituições de ensino, com o intuito de prevenir os futuros casos de depressão no contexto escolar, exercendo, assim, o papel de promotores de saúde.

\section{Referências}

Abric, J. C. (1987). Coopération, compétition et représentations sociales. Cousset: Delval.

Ajuriaguerra, J., \& Marcelli, D. (1991). Manual de psicopatologia infantil. Porto Alegre: Artmed.

Andriola, W. B., \& Cavalcante, L. R. (1999). Avaliação da depressão infantil em alunos da préescola. Psicologia: Reflexão e Crítica, 12(2), 419-428.

Arruda, A. (2002). A teoria das representações sociais e teoria de gênero. Caderno de Pesquisa, 117, 127-147.

Bahls, S. C. (2002). Aspectos clínicos da depressão em crianças e adolescentes: Clinical features. Jornal de Pediatria, 78(5), 359-366.

Ballone, G. J. Depressão. 2002. Retirado em 06 maio 2007, de http://www.psiqweb.med.br/ deptexto.html.

Ballone, G. J. Depressão na infância. 2004. Retirado em 04 março 2008, de http:// www.psiqweb.med.br/geriat.

Bandim, J. M., Roazzi, A., \& Doménech, E. (1998). Rendimento escolar em crianças com sintomas depressivos. Jornal Brasileiro de Psiquiatria, 47(7), 353-60.

Baptista, C. A., \& Golfeto, J. H. (2000). Prevalência de depressão em escolares de 7 a 14 anos. Revista de Psiquiatria Clínica, 27(5), 253-255.

Barbosa, G. A., \& Gaião, A. A. (2001). Apontamentos em psicopatologia infantil. João Pessoa: Idéia.

Barbosa, G. A., Dias, M. R., Gaião, A. A., \& Lorenzo, W. C. G. (1995). Depressão Infantil: Um estudo de prevalência com CDI. Infanto: Revista de Neuropsiquiatria da Infância e Adolescência, 4(3), 36-40. 
Bardin, L. (2002). Análise de conteúdo. Lisboa: Edições 70 .

Barreto, A. (1993). Depressão e cultura no Brasil. Jornal Brasileiro de Psiquiatria, 42(Supl.), 13-16.

Barros, A. P. R., \& Coutinho, M. P. L. (2005). Depressão na adolescência: Representações sociais. In M. P. L. Coutinho \& A. A. W. Saldanha (Orgs.), Representação social e práticas de pesquisa (pp.39-67). João Pessoa: Ed. Universitária UFPB.

Calderaro, R. S. S., \& Carvalho, C. V. (2005). Depressão na infância: Um estudo exploratório. Psicologia em Estudo, 10(2), 181-189.

Camon, V. A. A. (2001). Depressão como um processo vital. In V. A. A. Camon (Org.), Depressão e psicossomática (pp. 1-44). São Paulo: Pioneira Thomson Learning.

Campos, D. M. S. (2005). O teste do desenho como instrumento de diagnóstico da personalidade (37a ed.). Petrópolis: Vozes.

Coutinho, M. P. L. (2005). Depressão infantil e representação social. João Pessoa: Ed. Universitária UFPB.

Cruvinel, M., \& Bowchovitch, E. (2004). Sintomas depressivos, estratégias de aprendizagem e rendimento escolar de alunos do ensino fundamental. Psicologia em Estudo, 9(3), 369-379.

Del Porto, J. D. (1999). Conceito e diagnóstico: Depressão. Revista Brasileira de Psiquiatria, 21(Supl.1), 6-11.

Doise, M. (1990). Lês representations sociales. In R. Ghiglione, C. Bonnet \& J. F. Richard (Orgs.), Traité de Psychologie Cognitive (Vol. 3, pp. 23 - 34). Paris: PUF.

Farr, R. (1994). Representações sociais: A teoria e sua historia. In P. Guareschi \& S. Jovchelovitch (Orgs.). Textos em Representação Sócial (pp 155-172). Petrópolis: Vozes.

Fleck, M. P. A., Lima, A. F. B. S., Louzada, S., Schestasky, G., Henriques, A., Borges, V. R., \& Camey, S. (2002). Associação entre sintomas depressivos e funcionamento social em cuidados primários à saúde. Revista de Saúde Pública, 36(4), 431-438.
Friedberg, R. D., \& McClure, J. M. (2004). A prática clínica de terapia cognitiva com crianças $e$ adolescentes. Porto Alegre: Artmed.

Goodyer, I. M. (1996). Physical symptoms and depressive disorder in childhood and adolescence. Journal of Psychosomatic Research, 41(5), 405-8.

Grillo, E., \& Silva, R. J. M. (2004). Manifestações precoces dos transtornos do comportamento na criança e no adolescente. Jornal de Pediatria, $80(2), 21-27$.

Holmes, D. S. (1997). Psicologia dos transtornos mentais. Porto Alegre: Artmed.

Kovács, M. J. (1992). Children Depression Inventory CDI: Manual. New York: Multi-Health Systems.

Jodelet, D. (2001). As Representações sociais. Rio de Janeiro: EdUERJ.

Lafer, B., \& Amaral, J. A. M. S. (2000). Depressão no ciclo da vida. Porto Alegre: Artmed.

Lagges, A. M., \& Dunn, D. W. (2003). Depression in children and adolescents. Neurologic Clinics, 21(4), 953-60.

Le Goff, J. (1991). O imaginário medieval. Lisboa: Editora Estampa.

Lima, D. (2004). Depressão e doenças bipolares na infância e adolescência. Jornal de Pediatria, 80(2), 11-20.

Lima, M. E. A. C., Garcia, D. F., \& Figueiredo, R. M. E. (2005). Depressão infantil: Um estudo em escola de periferia de Belém. In L. C. de Abuquerque (Org.), Estudos do Comportamento. Belém: EDUFPA.

Miller, J. (2003). O livro de referência para a depressão infantil. (M. M. Tera, Trad.). São Paulo: M. Books.

Moscovici, S. (1961). La psychanalyse son image et son public. Paris: Presses Universitares de France.

Moscovici, S. (2003). Representações sociais: Investigação em Psicologia Social. Petrópolis, RJ: Vozes.

Oliveira, D., Sá, C. P., Fischer, F. M., Martins, I. S., \& Teixeira, R. L. (2001). Futuro e liberdade: O trabalho e a instituição escolar nas representações sociais de adolescentes. Estudos de Psicologia, 6(2), 245-258. 
Oliveira, J. S. C.; Ribeiro, K. C. S., Araújo, L. F., \& Coutinho, M. P. L. (2006). Representações sociais da depressão elaboradas por crianças com sintomatologia depressiva: Mudanças. Psicologia da Saúde, 14(2), 160-170.

Palosaari, U., \& Aro, H. (1994). Effect of timing of parental divorce on the vulnerability of children to depression in young adulthood. Adolescence, 29(115), 681-90.

Pearce, J. B. (1978). The recognition of depressive disorder in children. Journal of the Royal Society of Medicine, 71, 494-500.

Puig-Antich, J. (1986). Psychobiological markers: Effects of age and puberty. In M. Rutter, C. E. Izard \& P. B. Read (Eds.), Depression in young people: Development and clinical perspectives (pp. 341-382). New York: Guilfort.

Reis, R. L. R., \& Figueira, I. L. V. (2001). Transtorno depressivo na clínica pediátrica. Revista Pediatria Moderna, 37, 212-222.

Sá, C. P. (1996). Núcleo central das representações sociais. Petrópolis, RJ: Vozes.

Scivoletto, S., \& Tarelho, L. G. (2002). Depressão na infância e adolescência. Revista Brasileira de Medicina, 59(8), 555-557.

Seligman, M. E. P. (1995). The optimistic child: A proven program to safeguard children against depression and build lifelong resilience. New York: Harper Perennial.

Souza, P. R. (1984). Depressão endógena em criança de oito anos: Relato de caso. Revista da Associação Brasileira de Psiquiatria, 6(21), 67-9.

Spitz, R., \& Nissen, G.(1983). Depressiones em la infancia y la adolescencia. Triângulo, 21(22-3), 73-87.

Trinca, W. (1976). Investigação clínica da personalidade: $O$ desenho livre como estímulo de apercepção temática. Belo Horizonte: Interlivres.

Vala, J. (2000). Representações sociais e psicologia social do conhecimento. In J. Vala \& M. B. Monteiro (Orgs.), Psicologia Social (4a ed.). Lisboa: Fundação Calouste Gulbenkian.
Versiani M., Reis, R., \& Figueira I. (2000). Diagnóstico do transtorno depressivo na infância e adolescência. Jornal Brasileiro de Psiquiatria, 49(10-12), 367-82.

Zavaschi, M. L. S., Satler, F., Poester, D., Vargas, C. F., Piazenski, R., Rohder, L. A. P., \& Eizirik, C. L. (2002). Associação entre trauma por perda na infância e depressão na vida adulta. Revista Brasileira de Psiquiatria, 24(4), 189-95.

Artigo recebido em 06/06/2007

Aceito para publicação em 15/09/2007

Endereço para correspondência:

Karla Carolina Silveira Ribeiro. Rua Enfermeira Ana Maria Barbosa de Almeida, 426 apto 403, Bancários. CEP: 58052-270, João Pessoa-PB, Brasil. E-mail: karlacribeiro@yahoo.com.br

Karla Carolina Silveira Ribeiro é mestranda em Psicologia Social pela Universidade Federal da Paraíba, pesquisadora do Núcleo de Pesquisa: Aspectos Psicossociais de Prevenção e Saúde Coletiva da Universidade Federal da Paraíba.

Josevânia da Silva Cruz de Oliveira é mestranda em Psicologia Social pela Universidade Federal da Paraíba, pesquisadora do Núcleo de Pesquisa: Aspectos Psicossociais de Prevenção e Saúde Coletiva da Universidade Federal da Paraíba.

Maria da Penha de Lima Coutinho é Professora Doutora, com Pós-Doutorado em Psicologia pela Universidade Aberta de Lisboa, Portugal, coordenadora do Núcleo de Pesquisa: Aspectos Psicossociais de Prevenção e Saúde Coletiva da Universidade Federal da Paraíba.

Ludgleydson Fernandes de Araújo é mestre em Psicologia Social, professor Assistente I do Departamento de Psicologia da Universidade Federal do Piauí, campus de Parnaíba, pesquisador do Núcleo de Pesquisa: Aspectos Psicossociais de Prevenção e Saúde Coletiva da Universidade Federal da Paraíba. 